American Journal of Applied Sciences 9 (5): 748-751, 2012

ISSN 1546-9239

(C) 2012 Science Publications

\title{
The Mathematical Model and Simulation of Static Var Compensator in Medium Transmission Line
}

\author{
Prechanon Kumkratug \\ Division of Electrical Engineering, Faculty of Engineering at Si Racha, \\ Kasetsart University, 199 M.6, Tungsukhla, Si Racha, Chonburi, 20230, Thailand
}

\begin{abstract}
Problem statement: The Static Var Compensator (SVC) have been widely investigated its effect on transient stability of Single Machine Infinite Bus (SMIB) system. The exact medium transmission line model in power system consists of the series resistance series reactance and shunt capacitance. It is not easy task to obtain the mathematical model of the SVC with the exact medium transmission line model for investigating transient stability performance. Approach: This study applied the concept of the two-port network to simplify the mathematical model of the power system. The full capacity of the SVC on transient stability improvement of the SMIB with the medium transmission line was then investigated. The proposed method was tested on sample system and compared on various cases. Results: The first swing of rotor angle curve of the faulted system without resistance was obviously higher than that of with resistance whereas the second swing of the faulted system without resistance was slightly less than that of with resistance. The system with a SVC could improve transient stability of power system. Conclusion: The SVC and resistance of the line can improve first swing of rotor angle. The resistance of the line provides negative effect on second swing of rotor angle. The simulation results indicate that for practical medium line, the resistance is very import parameters for evaluating transient stability of power system.
\end{abstract}

Key words: Power system stability, transient stability, critical clearing time, FACTS devices, resistance, reactance, capacitance, transmission line, medium transmission line, two-port network, Static Var Compensator (SVC)

\section{INTRODUCTION}

Because of environmental legislation, rights-ofway issues, costs of construction and deregulation policies that introduced in recent years, now power engineers have been forced to fully utilize the existing power system. A number of Flexible AC Transmission System (FACTS) controllers, based on the rapid development of power electronics technology, have been proposed for better utilization of the existing transmission systems (Kejun et al., 2010; Kumkratug, 2010; Magaji and Mustafa; 2009; Luiz et al., 2009; Omar and Sulaiman, 2010; Osuwa and Igwiro, 2010; Rosli et al., 2010; Sona and Rajaram, 2011; ZarateMinano et al., 2010).

The Static Var Compensator (SVC) is the shunt FACTS devices. It consists of the capacitor bank reactor bank and thyristors as shown in Fig. 1. The thyristors control the reactance or susceptance that dictates the power flow through a line. The SVC can be applied for improving transient stability of power system (Mustafa and Magaji, 2009).

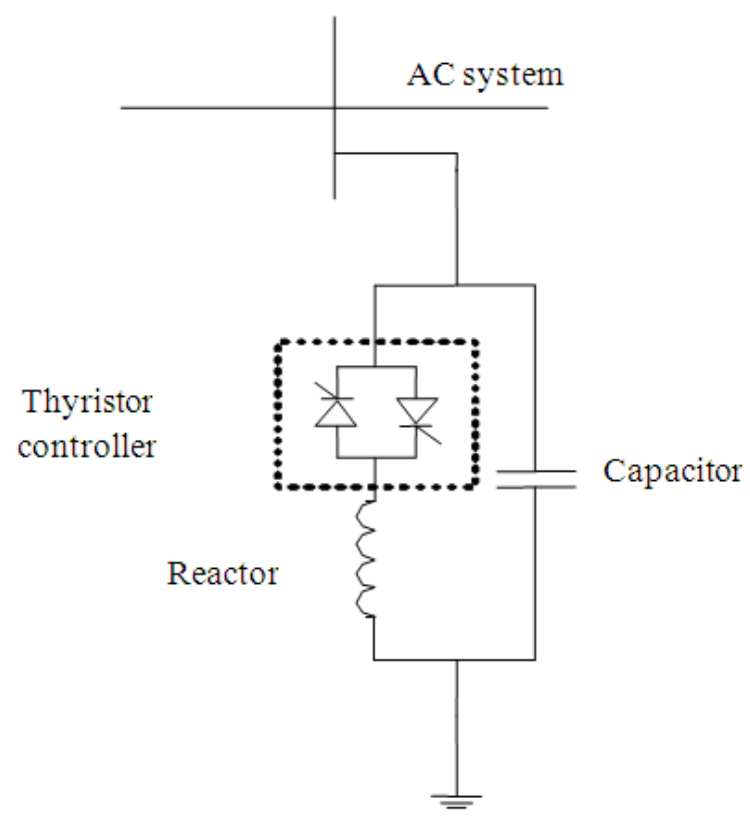

Fig. 1: Schematic diagram of SVC 
This study will investigate the capability of the SVC on transient stability of the SMIB system with the exact medium transmission line model. The concept of two-port network is applied to simplify the mathematical model of the power system. The sample system consisting the practical medium transmission line is used to investigate in this study. The proposed method is tested on various cases.

\section{MATERIALS AND METHODS}

Mathematical model: Figure 2a shows the single line diagram of power system consisting of a generator, a transformer, four medium transmission lines and SVC. Fig. 2b shows the equivalent of Fig. 2a. The generator is represented by a synchronous voltage in quadrature axis $\left(\mathrm{E}_{\mathrm{q}}{ }_{\mathrm{q}}\right)$ behind direct transient reactance $\left(\mathrm{X}_{\mathrm{d}}{ }_{\mathrm{d}}\right)$. The $\mathrm{V}_{\mathrm{b}}$ is the voltage at infinite bus. The exact medium transmission line model is represented by the impedance $\left(Z_{L}\right)$ which consists of a resistance $\left(R_{L}\right)$ and reactance $\left(\mathrm{X}_{\mathrm{L}}\right)$. The $\mathrm{SVC}$ can be modeled as the variable shunt susceptance $\left(\mathrm{B}_{\mathrm{SVC}}\right)$ as shown in Fig. 2 b. This study will apply the concept of the two-port network to simplify the equivalent in Fig. 2b. Each component of power system and a SVC can be represented the matrix of two-port networks (A, B, C and D) as shown in Fig. 2c and given by Eq. 1-8:

$$
\begin{aligned}
& \mathrm{A}_{1}=\mathrm{A}_{2}=\mathrm{A}_{3}=\mathrm{A}_{4}=\mathrm{A}_{5}=\mathrm{A}_{6}=\mathrm{A}_{\mathrm{SvC}}=1 \\
& \mathrm{~B}_{1}=\mathrm{jX_{ \textrm {d } } ^ { \prime }} \\
& \mathrm{B}_{2}=\mathrm{j} \mathrm{X}_{\mathrm{t}}^{\prime} \\
& \mathrm{B}_{3}=\mathrm{B}_{4}=\mathrm{B}_{5}=\mathrm{B}_{6}=\mathrm{jZ}_{\mathrm{L}} \\
& \mathrm{B}_{\mathrm{TCSC}}=0 \\
& \mathrm{C}_{1}=\mathrm{C}_{2}=\mathrm{C}_{3}=\mathrm{C}_{4}=\mathrm{C}_{5}=\mathrm{C}_{6}=0 \\
& \mathrm{C}_{\mathrm{TCSC}}=\mathrm{jB}_{\mathrm{svc}} \\
& \mathrm{D}_{1}=\mathrm{D}_{2}=\mathrm{D}_{3}=\mathrm{D}_{4}=\mathrm{D}_{5}=\mathrm{D}_{6}=\mathrm{D}_{\mathrm{svC}}=1
\end{aligned}
$$

It can be seen from the Fig. 2c that some ports are in series and in shunt connection. For example, a port 1 and port 2 are in series connection whereas port 3 and port 4 are in shunt connection. Thus with the series combination of port 1 and port 2, a new port is given by Eq. 9-12:

$$
\mathrm{A}_{\mathrm{s}}=\mathrm{A}_{1} \mathrm{~A}_{2}+\mathrm{B}_{1} \mathrm{C}_{2}
$$

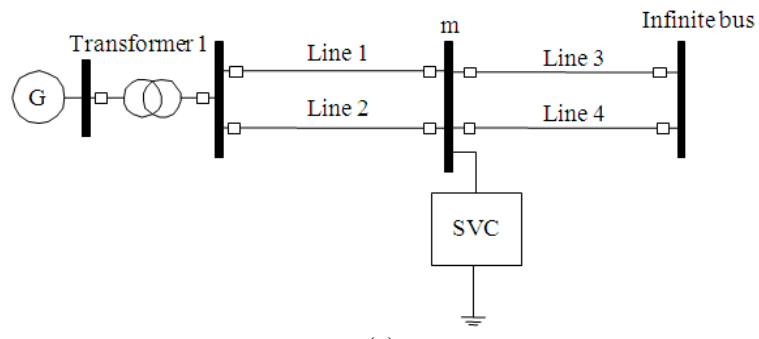

(a)

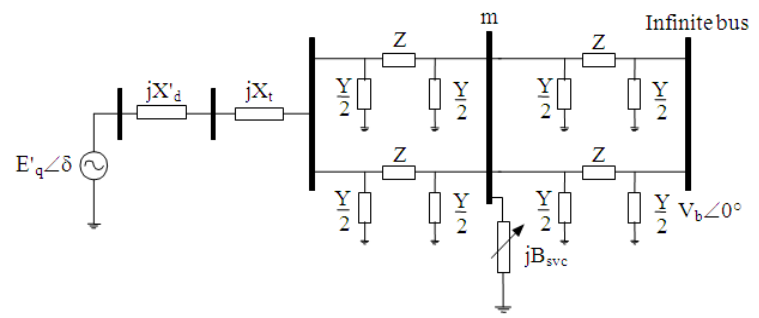

(b)

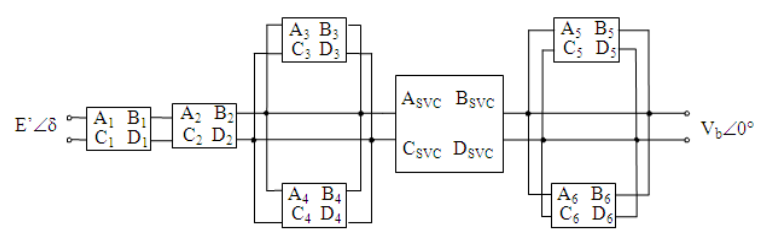

(c)

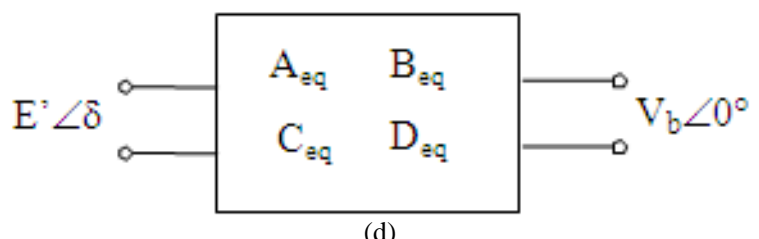

(d)

Fig. 2: Single machine infinite bus system with a SVC (a) schematic diagram (b) equivalent circuit (c) two -port networks diagram (d) the net two-port network

$\mathrm{B}_{\mathrm{s}}=\mathrm{A}_{1} \mathrm{~B}_{2}+\mathrm{B}_{1} \mathrm{D}_{2}$

$\mathrm{C}_{\mathrm{s}}=\mathrm{A}_{2} \mathrm{C}_{1}+\mathrm{C}_{2} \mathrm{D}_{1}$

$\mathrm{D}_{\mathrm{s}}=\mathrm{B}_{2} \mathrm{C}_{1}+\mathrm{D}_{1} \mathrm{D}_{2}$

Similarly, with the shunt combination of port 3 and port 4, a new port is given by Eq. 13-16:

$\mathrm{A}_{\mathrm{sh}}=\left(\mathrm{A}_{3} \mathrm{~B}_{4}+\mathrm{A}_{4} \mathrm{~B}_{3}\right) /\left(\mathrm{B}_{3}+\mathrm{B}_{4}\right)$

$\mathrm{B}_{\mathrm{sh}}=\mathrm{B}_{3} \mathrm{~B}_{4} /\left(\mathrm{B}_{3}+\mathrm{B}_{4}\right)$

$\mathrm{C}_{\mathrm{sh}}=\mathrm{C}_{1}+\mathrm{C}_{2}+\left(\mathrm{A}_{1}-\mathrm{A}_{2}\right)\left(\mathrm{D}_{2}-\mathrm{D}_{1}\right) /\left(\mathrm{B}_{1}+\mathrm{B}_{2}\right)$ 
$\mathrm{D}_{\mathrm{sh}}=\left(\mathrm{B}_{4} \mathrm{D}_{3}+\mathrm{B}_{3} \mathrm{D}_{4}\right) /\left(\mathrm{B}_{3}+\mathrm{B}_{4}\right)$

With the above concepts, the net two-port network diagram is shown in Fig. 2d. Here $A_{\text {eq }}, B_{\text {eq }}, C_{\text {eq }}$ and $D_{\text {eq }}$ are the element in net matrix of net two-port networks.

The output electrical power of synchronous machine $\left(\mathrm{P}_{\mathrm{e}}\right)$ Eq. 17:

$P_{e}=\frac{A_{\text {eq }}\left(E_{q}^{\prime}\right)^{2}}{B_{\text {eq }}} \cos \left(\theta_{\text {Beq }}-\theta_{\text {Aeq }}\right)-\frac{\mathrm{V}_{\mathrm{b}} E_{q}^{\prime}}{B_{\text {eq }}} \cos \left(\theta_{\text {Beq }}+\delta\right)$

Here:

$\mathrm{A}_{\text {eq }}=\mathrm{A}_{\text {eq }} \angle \theta_{\text {Aeq }} \mathrm{B}_{\text {eq }}=\mathrm{B}_{\text {eq }} \angle \theta_{\text {Beq }}$

The dynamic equation for evaluating critical clearing tine of the system in Fig. 2a is given by Eq. 18:

$\dot{\delta}=\omega$

$\dot{\omega}=\frac{1}{\mathrm{M}}\left[\mathrm{P}_{\mathrm{m}}-\mathrm{P}_{\mathrm{e}}\right]$

Here, $\delta, \omega$ and $\mathrm{P}_{\mathrm{m}}$ as given in Eq. 18-19 are the rotor angle, speed, mechanical input power and moment of inertia, respectively of synchronous machine. The $\mathrm{P}_{\mathrm{e}}$ is the output electrical power of synchronous as given in Eq. 15.

It can be mentioned here that the variable shunt susceptance of the SVC as given in Eq. 7 is changed during the dynamic state for improve the transient stability. This study uses the linear control given by Eq. 20:

$\mathrm{B}_{\mathrm{svC}}=\mathrm{K} \omega$

Here, $\mathrm{K}$ is the constant gain control.

\section{RESULTS}

Consider the diagram of sample system is shown in Fig. 1a. The system data are.

Generator: $\mathrm{H}=5, \mathrm{X}_{\mathrm{t}}=0.1 \mathrm{pu}, \mathrm{X}_{\mathrm{d}}{ }^{\prime}=0.20 \mathrm{pu}, \mathrm{E}_{\mathrm{q}}{ }=$ $1.22 \angle 31.64 \mathrm{pu}$. Transmission line data: Voltage level $345 \mathrm{kV}, 130 \mathrm{~km}, \mathrm{f}=50 \mathrm{~Hz}, \mathrm{R}=0.036 \Omega \mathrm{km}^{-1}, \mathrm{~L}=0.8$ $\mathrm{mH} \mathrm{km}{ }^{-1}, \mathrm{C}=0.0112 \mu \mathrm{F} \mathrm{km}^{-1}$. Thus the impedance (Z) and the admittance ( $\mathrm{Y}$ ) of the medium line at fundamental frequency are $\mathrm{Z}=4.68+\mathrm{j} 32.6726 \mathrm{ohm}$ and $\mathrm{Y}=0+\mathrm{j} 0.000457416$ Siemens, respectively. The percentage of $\mathrm{R} / \mathrm{X}$ and $\mathrm{B}_{\mathrm{c}} / \mathrm{X}$ of the line are $=14.32 \%$ and $\mathrm{B}_{\mathrm{c}} / \mathrm{X}=0.0014 \%$, respectively. With the given reactance of the line $(\mathrm{X})=0.5 \mathrm{pu}$, the per unit of $\mathrm{R}$ and $\mathrm{B}_{\mathrm{c}}$ are 0.0716 and $7 \times 10^{-6} \mathrm{pu}$, respective.

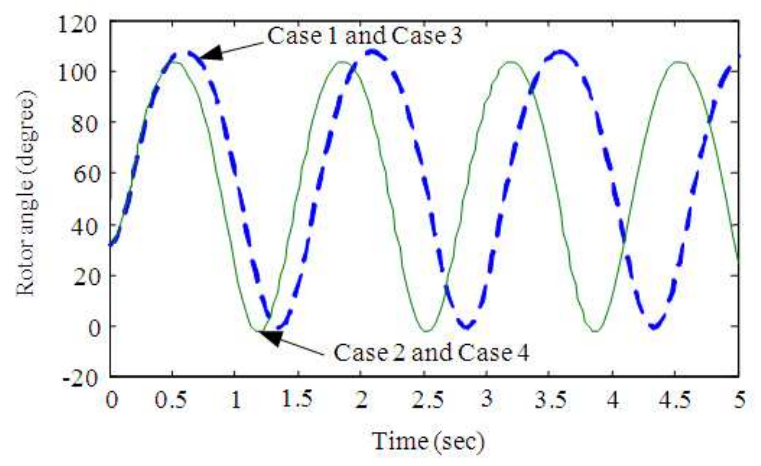

Fig. 3: The rotor angle of the system without SVC for $\mathrm{tcl}=170 \mathrm{~m} \mathrm{sec}$

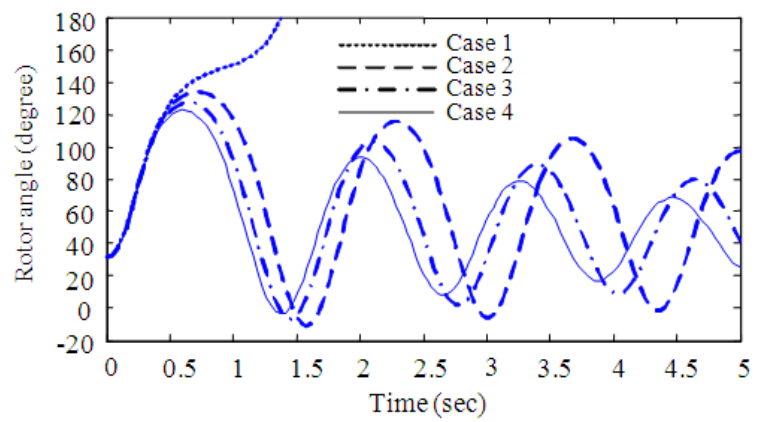

Fig. 4: The rotor angle of the system with various gains of a SVC for tcl $=210 \mathrm{~m} \mathrm{sec}$

Table 1: The maximum and minimum rotor angle of the system without SVC

\begin{tabular}{lllll}
\hline Case & $\mathrm{R}$ & $\mathrm{B}_{\mathrm{c}}$ & $\delta_{\max }($ degree $)$ & $\delta_{\min }($ degree $)$ \\
\hline 1 & 0.0000 & 0 & 107.80 & -0.63 \\
2 & 0.0716 & 0 & 103.74 & -2.77 \\
3 & 0.0000 & $7 \times 10^{-6}$ & 107.80 & -0.63 \\
4 & 0.0716 & $7 \times 10^{-6}$ & 103.74 & -2.77 \\
\hline
\end{tabular}

Table 2: The maximum and minimum rotor angle of the system with various gains of a SVC for tcl $=210 \mathrm{~m} \mathrm{sec}$

\begin{tabular}{lllc}
\hline Case 1 & $\mathrm{~K}$ & $\delta_{\max }($ degree $)$ & $\delta_{\min }($ degree $)$ \\
\hline 1 & 0 & - & - \\
2 & 10 & 134.12 & -10.87 \\
3 & 20 & 127.62 & -7.01 \\
4 & 30 & 122.82 & -3.54 \\
\hline
\end{tabular}

It is considered that three phase fault appears at line 2 near bus $m$ and the fault is cleared by opening circuit breakers at the end of the line. Figure 3 shows the rotor angle of the system without a SVC $(\mathrm{K}=0)$ for the clearing time $\left(\mathrm{t}_{\mathrm{cl}}\right) 170 \mathrm{~m} \mathrm{sec}$. Table 1 summaries the maximum and minimum rotor angles $\left(\delta_{\max }, \delta_{\min }\right)$ of Fig. 3.

Figure 4 shows the rotor angle of the system with various gains $(\mathrm{K})$ of a SVC. In the Fig. 4, the exact medium transmission line model is considered. In 
this case the constant gain control is changed. Table 2 summarizes the maximum and minimum rotor angle of the system.

\section{DISCUSSION}

It can be seen from the Fig. 2 and Table 1 that resistance of the medium line provides the improvement of the first swing stability but not for the second swing. Without the resistance of the medium line, the maximum and the minimum rotor angle are 107.80 and $-0.63^{\circ}$, respectively whereas with the resistance, the maximum and the minimum rotor angle are 103.74 and $-2.77^{\circ}$, respectively.

The proposed model provides the success of investigating the effect of the SVC on transient stability improvement of the SMIB system. It was found from the simulation results that the stability gets increase as the gain of a SVC is increased.

\section{CONCLUSION}

This study investigated the effects of the Static Var Compensator (SVC) on transient stability improvement of the Single Machine Infinite Bus (SMIB) system with the consideration of the exact medium transmission line model. The mathematical model was systematically derived by using the concept of the two-port network. This concept can help us to obtain mathematical model of the system in the simpler way.

The presented methods were tested and compared on various cases. It was found from the simulation results that the SVC improve the transient stability performance both first swing stability and other swings whereas the resistance of the line provides the improvement of the first swing but not for the second swing.

\section{REFERENCES}

Kejun L., Jianguo Z., Chenghui Z. and Wei-Jen L., 2010. Dynamic simulator for thyristor-controlled series capacitor. IEEE Trans. Ind. Appli., 46: 10961102. DOI: $10.1109 /$ TIA.2010.2046283

Kumkratug, P., 2010. Application of interline power flow controller to increase transient stability of power system. J. Comput. Sci., 6: 1490-1493. DOI: 10.3844/jcssp.2010.1484.1487

Magaji, N. and M.W. Mustafa, 2009. Optimal thyristor control series neuro-controller for damping oscillations. J. Comput. Sci., 5: 983-990. DOI: 10.3844/jcssp.2009.980.987

Mustafa, M. W. and N. Magaji, 2009. Optimal location of static var compensator device for damping oscillations. Am. J. Eng. Applied Sci., 2: 353-359. DOI: 10.3844/ajeassp.2009.353.359

Osuwa, J.C. and E.C. Igwiro, 2010. Uninterruptible power supply using solar rechargeable battery. Phys. Int., 1: 77-82. DOI: 10.3844/pisp.2010.77.82

Rosli, O., Nasrudin A.R. and Marizan, S., 2010. New control technique applied in dynamic voltage restorer for voltage sag mitigation. Am. J. Eng. Applied Sci., 3: $\quad 42-48 . \quad$ DOI: 10.3844/ajeassp.2010.42.48

Sona, P. and M. Rajaram, 2011. Fuzzy logic controller for static synchronous series compensator with energy storage system for transient stability analysis. J. Comput. Sci., 7: 859-864. DOI: 10.3844/jcssp.2011.859.864

Zarate-Minano, R., T.V. Custsem, F. Milano and A.J. Conejo, 2010. Sexuring transient stability using time domain simulations within an optimal power flow. IEEE Trans. Power Syst., 5: 243-253, DOI: 10.1109/TPWRS.2009.203069 